\title{
Binding Conventions for Music Materials
}

\section{Edie Tibbits}

\begin{abstract}
Many procedures common in the binding of books are not feasible for use with music scores. A small sample of academic libraries was surveyed about many of the special considerations required in the establishment of local binding procedures for music scores. Strictly from a preservation standpoint, many practices of the libraries in this survey sample are not sound. There is a growing level of communication among music publishers and music librarians about the "preservability" of published music. Carefully established binding practices are of paramount importance if a music collection is to serve the public of the music library for an extended length of time.
\end{abstract}

$\mathbf{L}$ ing budgets, increased service demands, and the fact that materials rapidly become out-of-print. Because the preservation and conservation of materials is recognized by library administrators as an area of growing importance, library planning necessarily includes an awareness of the preservation needs of an institution's many and varied collections. Preservation in any library collection includes components such as climate control, light exposure, shelving, pest control, disaster preparedness plans, and binding and shelving practices. Few, if any, libraries can afford the provision of "optimum care" for all materials in their collection (Godden 1991, 222). Binding materials and practices have a clear impact on the shelf life of library materials. Various materials in most collections are bound in different styles based on their age, value, and intended use (Johnson 1978, 7). In library budgets, binding has traditionally been given low priority in relation to other budget items (Bloomberg 1985, 28). As replacement costs of materials continue to increase, priorities for binding and preservation are being reevaluated in the costcutting environment of today's institutions.

Because of their printed formats and use, music materials require special attention when considering binding options. Music binding must accommodate the special needs of both the practicing musician and the music scholar. The finished volume should be flexible, able to stand open on a stand or music rack, and lay flat on any surface (Roberts 1976, 752). It must also be able to withstand repeated openings and closings. As the cost of paper continues to escalate, the margins of all printed materials are becoming more narrow (Roberts 1976, 761). This is an especially crucial point for music materials, where the margins are already quite small. Innovations by music publishers, such as plastic or wire spiral bindings, exacerbate the problems of narrow margins. Most

EDIE TIBbITs is Music and Rare Books Cataloger at the Joyner Library, East Carolina University (editib@joyner.lib.ecu.edu). Manuscript received July 7, 1995; revised August 19, 1995; accepted for publication September 12, 1995. 
music is published in limited editions and goes out-of-print very quickly. Gottlieb (1994, 30) points out that, while reprint editions are common, it can be difficult to determine which particular edition is being reprinted. Because musicians are frequently concerned with the particular edition of a score to be used for study or performance, the identification of reprints is vital for some music library patrons.

\section{BACKGROUND}

The binding of music scores with parts presents other problems as well. As music librarians know, scores are frequently very thin. A score is often accompanied by parts that are to be kept with the score as a unit. Parts might be printed so that they have two open pages on a single leaf, which is to be turned completely over for the next two pages. This does not allow binding to be attached. Scores issued with parts are difficult to preserve as sets. Older scores and some foreign scores are printed on very poor quality paper. Scores often are made in odd sizes (frequently over thirty-six centimeters or, conversely, less than twenty centimeters high). Finally, scores frequently receive very heavy use by music library patrons.

Music, because it requires special treatment, has become a major exception to ordinary binding techniques. As an exception, music binding generally is more expensive than ordinary book binding (Miller 1966, 60). However, it should be noted that binding extends the shelf life of a score by a factor of four or five (Falconer $1973,335)$. Binding is a major expense in the operation of a music library, but it is difficult to assess the impact of binding costs on music library budgets because few academic libraries have a music binding budget that is maintained separately from that of the library as a whole. (In the sample for this paper, only one library could provide a binding budget figure that was exclusively for music materials.)

\section{STANDARDS}

To date, there have been no official standards adopted by the American Library As- sociation (ALA), the Music Library Association, or the Library Binding Institute for the binding of music materials. The eighth edition of the Library Binding Institute Standard for Library Binding makes no special provisions for printed music, but has several sections that are relevant. Sections 6.2 (Sewing through the fold), 6.2.2.1 (Sewing through the fold by hand), 10 (Thread), and 19 (Sewing types) all relate to music binding. Even when there are accepted standards, library binding decisions will still need to be based on the type of library collection and the objectives of the institution (Honea 1989, 144).

\section{Formatting Problems}

There has been an increasing reliance by music publishers on plastic or wire spiral binding in recent years. These scores are usually printed with very small margins that make adhesive binding difficult because musical symbols cannot be sacrificed to the binding. Although some professional binderies will sew them or use adhesive binding, the results might not stand up to heavy use. Spiral binders present a major challenge in the music library.

Classic procedures for the pam-binding of music materials are detailed in Falconer's article "A Handiguide to Do-ItYourself Music Binding" (Falconer 1973). She indicates that leaves must be sewn through the fold. All staples should be removed because they rust rapidly, break away, and result in detached and weakened pages contaminated with rust (Honea 1989, 148). Staples might also fail to grip all of a signature and are difficult to drive straight through the center fold. Off-center staples can result in tears the first time a score is opened (Miller 1966, 59). Loose leaves must be tipped in or stubbed with paper and sewn in with the other pages. Enclosures need to be provided for thin scores and parts. Care must be taken to bind neither performance parts in with the score nor parts displaying two consecutive pages on one side of a folded sheet of paper. Solid cover binders require additional labeling with composer 
and title. All parts must be labeled. Binders should also be marked for contents (i.e., 1 score +4 parts). There should be a notation on the binder as to how many parts are included (i.e., Includes $\mathrm{x}$ no. parts) to allow the staff at the circulation desk to verify that the complete set is sent out and returned. Music binding requires extra time and training for the library staff doing the work. When deciding which scores are to be sent out for professional binding, basing part of the decision on the thickness and weight of the score is certainly appropriate. Each score must be considered individually and attentively before any decision about binding can be made.

\section{Shelving Problems}

Shelving music scores presents additional headaches for the librarian. The physical size of the piece alone can be problematic. Contemporary music is often printed on very large sheets that are sometimes published as a set of single-sided leaves. Because so many scores are published in a format larger than thirty-one centimeters (the traditional breaking point for most oversize book collections), it makes sense to allow a larger figure for the height or breadth of a score to determine the spacing of general shelving in the music library.

Ideally, special shelving can be purchased for these oversize materials, . but there are occasions when oversize scores must be shelved with the rest of the collection. Often, scores with plastic spiral bindings are large and sometimes include separate unbound parts, presenting enormous problems for shelving in the music library. They cannot stand on the shelf without reinforcement. If they are held in place only by smaller neighboring volumes, they might warp or curl (Honea 1989, 147-48).

Difficulties are also presented by the size of miniature scores. (A miniature score is one created for study purposes and in which the notation is too small to be used for performance.) Miniature scores come in many sizes. Some measure eighteen centimeters, while others are thirty-six centimeters in height. Shelving the small scores with taller materials means that some miniatures will inevitably end up inside the binding of larger scores or pushed to the very back of the shelf where they might fall between the shelves. A decision to shelve miniature scores with larger scores or to shelve them separately must be carefully considered.

Music libraries have particular shelving problems beyond the height and bulk elements discussed above. The binding boards on music materials might be thicker than the score within the binding. Thus, it is necessary to allow extra linear feet for these materials in shelving plans. Because so many scores are very thin, there are few spine labels to be read from the front of the shelf. Thick or professionally bound scores can easily hide thin pambound ones. It is possible to put only the call number on each separate piece, and with clear-covered binders that might be sufficient. But if solid cover binders are used, most patrons would agree that some sort of additional labeling is needed. Very often, the most helpful label information is the composer and title or the title alone. Depending on the placement of this information, the library patron must pull each volume off the shelf for identification until the correct score is located. The additional pulling and pushing of scores on the shelves aggravates the problem of miniature scores falling behind the shelves and increases the risk of torn pages.

No matter what labeling is applied, maintenance of a range of scores can be tedious at best. Anyone working with a curriculum or children's collection will easily identify with the situation. Hundreds of very thin pieces of varying sizes fit in a short section of a range. Shelf reading can be a nightmare!

\section{Circulation Problems}

The circulation of music scores presents additional complications. If the score comes with performance parts, are these parts going to be circulated separately or with the score? Will each separate piece be barcoded? How will the complete score and all of its parts be kept together? 
If the parts are kept in the binding of the score, how is the circulation record going to be maintained? Will the parts be counted by staff each time they are returned by the library patron? Will the library staff understand the importance of that additional task in the circulation of music materials? If the parts are circulated separately, how will they be protected? Many contemporary pieces are printed on single leaves of paper with one page per leaf. How are the leaves of each part to be kept together and yet separate from the other parts? How is the integrity of the score and parts going to be maintained?

\section{LITERATURE REVIEW}

A review of the literature on music binding policies revealed only nine articles or chapters dealing specifically with the binding of music materials. Another ten titles relating to general pam-binding practices used in libraries were identified as potentially relevant to music binding policies. The complexities of preservation cannot be addressed within the limits of this paper. Knowing the Score: Preserving Collections of Music (Roosa 1994) is just one source of information concerning preservation issues for paper music materials.

\section{METHODOLOGY}

A survey was made of a carefully selected sample of academic libraries for which in-house pam-binding of scores is done. Questionnaires were sent out by e-mail to people involved with music binding decisions and the circulation of music scores at twenty libraries. The libraries chosen for comparison are all accredited by the National Association of Schools of Music and are similar in three variables: the number of music majors registered at the school, the size of the teaching faculty, and the number of music scores in the library collection. Based on these variables the following schools were contacted for comparison purposes: Brigham Young University, City University of New York at Queens, East Carolina University, Ithaca
College, James Madison University, Kent State University, Michigan State University, Shenandoah College \& Conservatory, Southern Methodist University, State University of New York-Potsdam, Temple University, the University of Akron, the University of Houston, the University of Kansas, the University of North Carolina at Greensboro, the University of Northem Colorado, the University of Utah, the University of Wisconsin-Milwaukee, West Virginia University, and Westminster Choir College. These schools all have 250-400 declared music majors, at least forty music faculty members, and collections containing $10,000-26,000$ scores. Libraries not responding to the e-mail survey were contacted by telephone. Southern Methodist University was dropped from the sample because their score collection is larger than reference sources had indicated. No contact could be established with the City University of New York at Queens; thus that library was also dropped from the sample.

The survey was conducted over a period of five months between May and September 1994. The survey of twenty libraries achieved a $90 \%$ response rate. Binding practices among these libraries vary widely as will be described below.

\section{Results}

Seven of the libraries consulted for this paper have bound $50 \%-75 \%$ of their score collection in-house. Five libraries bind $10 \%-40 \%$ of their scores themselves. For only two library collections are all scores currently being sent out for professional binding. Conversely, one library binds $90 \%$ in-house. For another, a percentage figure could not be determined.

One institution reported that over $\$ 11,000$ was spent in one year for the binding of music. This figure does not include other binding sent by the library to a professional binder. Of all the libraries considered for this paper, this was the only one with a binding budget for music materials that is separate from the total library binding budget. If more library administrators were aware of the actual costs of binding music, it is safe to assume that 
pam-binders and supplies might achieve a higher priority in the supply budgets of many institutions.

Decisions as to the appropriate binding to be used for scores almost always involve the music librarian, an assistant in the music library, or the music cataloger. A library might have formalized binding procedures that prescribe a specific type of binding for standing orders, approval plan materials, and firm orders, or that define other clear parameters for the decision based on the size, cost, or paper quality of the score. These procedures might allow someone in the general library technical processing, preservation, or bindery area to make the binding decision following strict guidelines.

Two of the libraries involved in this study have in-house binding done by preservation departments or someone specifically identified outside the music library to do the work. In these two instances, binding decisions are made by these specialists in consultation with the music librarian or cataloger. There was only one instance reported where the decision is made without the participation of the music librarian. In this library, binding decisions are made by the head of the acquisitions department.

Decisions as to the type of binding to use for scores (pam-binder, portfolio, box, or professional binding) involve many variables. In this survey, the size of the score was the most common element cited for this decision. The number of signatures contained in the cover is used by two libraries in the sample, and the cost of the original score is used in another. The thickness (or bulk) of the volume was cited as a factor in the decision process by six libraries. The quality of the paper, which has some impact on the way the material sits on a music stand, is taken into consideration by two libraries. Some scores from east European and Asian publishers are printed on very thin paper with little or no bulk. This helps cut the costs of shipping these scores overseas, but can result in large pages not sitting well on the music stand for performance.

The use to which the score will be put was mentioned as an important factor in the decision by two of the libraries consulted. Is it going to lay on a flat surface as a study score would, or is it going to be placed on the music rack of a piano or organ or on a music stand?

Pam-binding can be a very labor-intensive task. Half of the institutions use student workers to actually perform the binding work. In one of these libraries, the binding is done by students while they cover a public service desk. One library requires that students go through rigorous training sessions to learn the basics of binding and the use of a book press. One librarian reported that his library no longer uses pam-binders, but prefers "class A binders," which was a term used in earlier binding specifications issued by the Library Binding Institute, and refers to hard, library-bound materials. In another library, the binding unit is part of the acquisitions department and is supervised by the head of acquisitions.

The method of attachment of the score to the binding has very strong implications for the life of a musical score. One library tapes or pastes scores to the binder. Another glues the signature if it is too thick to be sewn. Two libraries use the adhesive strips in the center of the pam-binders they purchase to hold the score in place. One of these institutions sometimes reinforces this adhesive with staples. Staples are used by two libraries in the work of binding. One of these libraries mentioned that scores bound in earlier times had been sewn.

The remaining eight libraries doing inhouse binding hand sew the signatures to the binder. (Only one respondent indicated specifically that staples are removed before the score is hand sewn.) Generally, there is little reinforcement of the page under the sewing or stapling. One library reinforces with cloth and another routinely uses tape to reinforce the innermost signature. One library with two special collections within its music library reinforces signatures under the sewing of only the scores added to those collections. Another provides reinforcement only if the score is very fragile.

There seem to be conflicting ideas about the placement of the score within a 
binder. One idea is to place the score flush with the bottom of the binder in order to keep the weight of the score from pulling it away from the binding. The other school of thought is to allow a bottom margin in the binding that would keep the piano rack or items on the music stand from tearing the pages each time they are turned. One-quarter of the libraries surveyed make the bottom of the score flush with the bottom of the binder. Sixty-three percent raise the score in the binder, but the distance varies. Some libraries raise it only one-eighth of an inch, others onequarter of an inch. Some prefer to raise it one-half an inch or more. Two of the libraries in this survey let the size of the binder dictate the placement of the score by simply centering it within the binder. One prefers to always center the score in the binding, while another keeps a variety of pam-binder sizes on hand and never cuts the boards to fit the size of a score.

Respondents agreed that parts should be kept on the shelf with the score as a bibliographic unit whenever possible. In three of the libraries consulted, the parts might be bound separately in a lightweight paper cover before being placed in a pocket at the back of the binding. Two libraries indicated that they sometimes pam-bind a cover when the parts are single leaves or are printed as four pages on a single sheet, and then place all the parts in a pocket.

Varying methods of linking the parts to the score are employed by the libraries in this survey. Most indicated that the call number of the score is written in pencil on each part. At one institution, the OCLC bibliographic record number is written on each part as well. One library barcodes each separate part and keeps them all in a pocket with the score. Each part must be checked out individually.

Most libraries have devised some method of alerting the person at the circulation desk about the presence of parts or loose leaves in a score binding. Stamps are put on the binder, pocket, or date-due slip that give the number of parts that are supposed to be present. Two libraries are planning to have a feature in their online system that will allow a note to appear on the circulation item record reminding staff to check for a specified number of parts. One library includes the instrumentation of the parts as part of the book label.

The need for special labeling on the binding of scores has been eliminated in some libraries by the use of pam-binders with clear covers. However, some preservation librarians are not yet convinced that the plastic of these covers will not do damage to the score after long use. When solid board covers are used to bind scores, labeling becomes extremely important. Only one library in this survey does not provide composer and title information in some form on the front of a solid cover binder.

At least two librarians contacted expressed concern about the patron having to pull the entire score off the shelf to read a label. Both of their institutions provide labeling along the spine or lengthwise on the binder, very close to the spine. In some institutions, extra labeling is done by the staff of the music library while the actual binding is done in a location central for the whole library. One music library photo-reduces the cover of the published work and glues this copy to the cover of the binder. Another library makes an effort to keep all the composer and title labels at a uniform height throughout the collection regardless of the height of the binder on which they appear.

Portfolios (a stiff case with four flap enclosures) or boxes are sometimes made in-house for music materials. One library has all portfolios made outside the library and does not use boxes. All rare material is removed from that music library and is added to the special collections department. Some libraries use a combination of boxes and portfolios made by a professional bindery and made in-house. Five of the libraries contacted make a concerted effort not to use portfolios or boxes. When such methods are needed, use is dictated by the type of protection required by the format or the condition of the materials. In three of the eighteen libraries in this study, both portfolios and boxes made inhouse are used for rare or brittle items, or for scores that are accompanied by parts that are much larger than the score or for 
which the parts are very thick. The labeling on the outside of all these containers in the libraries surveyed is the same as that done for scores.

Certain music publishers are showing an increased reliance on spiral binding for twentieth century music. These scores are often large in dimension, but cover a wide range in terms of pagination, from very thin to fifty or seventy-five pages. As was mentioned earlier, these scores present a major problem for music libraries. In this sample, six libraries shelve spiral-bound scores "as is" with some provision for sending them to a professional bindery when it becomes necessary. One library tapes the "very thin" ones in a pam-binder. Another sends those that are expensive to a binder if the margins are wide enough to be trimmed. If the margins are too narrow to allow professional binding, one library keeps expensive spiral-bound scores in a closed stack area on a "permanent reserve" basis. Most of the other libraries in this survey reinforce the covers with lamination or pressboard. One of these institutions also reinforces the spiral binding itself with plastic tape that is then attached to the strengthened covers. Two libraries place spiral bindings in a pocket in a pam-binder when possible. One library routinely places spiral-bound scores in boxes when they cannot be trimmed for binding. Another has devised a method of "lacing" these scores and then using a pam-binder. It was not clear what was meant by "lacing," but it seemed that the procedure was not the same as "lace-backing" a book. Three libraries mentioned that they try to avoid the problem by not buying spiral-bound scores for their collections.

A final consideration in the binding of music scores is the shelving of the items. There has been a discussion on the Internet recently of the idea of shelving the entire library collection in one call number run, intershelving oversize, miniature, videorecordings, sound recordings, computer software, and so on. No one in this survey follows that practice within the music library. Only one library intershelves both miniature scores and oversize with "regular" materials. Another li- brary shelves all sizes of print materials together with the exclusion of oversize materials. Half of the libraries in the survey maintain three call number sequences for scores: one for "regular" materials, one for oversize, and one for miniature scores. One library has one sequence each for "regular," oversize, and folio. Two libraries further divide this organization by distinguishing oversize as either quarto- or folio-. The remaining four libraries have only two divisions, "regular" and oversize. As a point of interest, the size of "oversize" varies from thirty-six to forty centimeters.

\section{Conclusions}

Strictly from a preservation standpoint, many practices of the libraries in this survey sample are not sound. To achieve any sort of preservation function, binders, pockets, labels, and tape must all be acidfree. Staples must be removed. Adhesive must be $\mathrm{pH}$ neutral PVA (polyvinyl acetate adhesive) to ensure long-time stability. Much research has been done on the preservation of books and paper. Much of this work can be applied directly to music materials. Scores at least look like a book and are generally made of paper.

However, music materials add a few variables not at issue for the preservation of books. Scores sold for performance purposes are frequently stapled into paper covers when published. They very often are published with a loose leaf in the center. The presence or absence of parts becomes an issue, because if each part is not to be bound separately, it must be linked in some way to the score. This usually means introducing glue or tape or extra covers that might influence the acid content of the item.

Musicians have traditionally been taught to "write it in" when given performance instructions. Most have learned to use pencil, but when a pencil is not at hand, anything will do! These markings can be seen as mutilation or, on occasion, they can add to the historical value of the score itself. Annotations in performance parts can create a problem for school, college, or university libraries trying to balance their attention between perform- 
ing and research functions (clean editions or containing the markings of a significant performer or conductor for research use versus heavily marked performance parts) (Honea 1989, 154).

There is a growing level of communication among music publishers and music librarians about the "preservability" of published music. The Music Library Association has an active Preservation Committee, which has presented workshops and preconferences in conjunction with the association's annual meetings and for meetings of the ALA, the Association of Recorded Sound Collections (ARSC), and the International Association of Music Libraries, Archives, and Documentation Centres (IAML).

Because professional binding costs are climbing rapidly, the proportion of items treated locally will certainly continue to grow. Music librarians need to be sure that their collections are adequately preserved and maintained. Besides providing a stable and acceptable environment in terms of heat, humidity, and lighting, preservation must involve careful control of the binding policies applied to all items in these collections. Because music scores go out-of-print so quickly, it is essential to begin preservation efforts immediately upon the receipt of the item in the library.

Attention must be given to the quality of the supplies used and to the training of the staff actually doing the work of binding. Carefully established binding practices are of paramount importance if a music collection is to serve the public of the music library for an extended length of time.

\section{Works CITED}

Bloomberg, Marty. 1985. Introduction to technical services for library technicians. Littleton, Colo.: Libraries Unlimited.

Falconer, Joan O. 1973. A handiguide to do-ityourself music binding. Wilson library bulletin 48: 332-35.

Godden, Irene P. 1991. Library technical services: Operations and management. $2 \mathrm{~d}$ ed. San Diego: Academic Press.

Gottlieb, Jane. 1994. Working against the odds: Preservation approaches in a conservatory library. In Knowing the score: Preserving collections of music, ed. Mark Roosa. Chicago: Association for Library Collections \& Technical Services, 12-34.

Honea, Ted. 1989. Conservation and preservation. In Modern music librarianship: Essays in honor of Ruth Watanabe, ed. Alfred Mann. Stuyvesant, N.Y.: Pendragon Press, 143-55.

Johnson, Arthur W. 1978. The Thames and Hudson manual of bookbinding. London: Thames and Hudson.

Lawton, Dorothy. 1937. Binding problems in music: Methods and costs. Notes 5 (Nov.): 24-28.

Library Binding Institute. 1986. Library Binding Institute standard for library binding. 8th ed. Rochester, N.Y.: The Library Binding Institute.

Merrill-Oldham, Jan, and Paul Parisi. 1990. Guide to the Library Binding Institute standard for library binding. Chicago: ALA.

Miller, Catharine K. 1966. Binding and circulation. In Manual of music librarianship, ed. Carol June Bradley. Ann Arbor, Mich.: Music Library Association, 58-64.

Roberts, Matt T. 1976. The library binder. Library trends 24 (Apr.): 749-62.

Roosa, Mark, ed.. 1994. Knowing the Score: Preserving collections of music. Chicago: Association for Library Collections \& Technical Services. 